\title{
Um testemunho do contemporâneo
}

\author{
Camila Dias de Souza Christo Aleixo \\ Universidade Federal de Ouro Preto
}

\begin{abstract}
Resumo
Estes escritos oferecem uma leitura do poema "Haste", pertencente à coletânea $\mathrm{A}$ dolorosa raiz do Micondó (2006), da escritora e jornalista Conceição Lima, natural de São Tomé e Príncipe. Considerado um testemunho poético e crítico sobre o tempo em que se vive, "Haste" parece deixar exposta uma realidade - um contexto de existência - hostil. Essa realidade afeta dolorosamente a relação entre ser e mundo exterior. A poesia se mostra, pois, como lugar possível para o testemunho dessa experiência marcada pela intempérie, bem como para a resistência diante de seus efeitos.
\end{abstract}

Palavras-chave: testemunho; contemporâneo; mau tempo.

\begin{abstract}
These writings offer a reading of the poem "Haste", from the collection A dolorosa raiz do Micondó (2006), by the writer and journalist Conceição Lima, native of São Tomé and Príncipe. Considered a poetic and critical testimony to the time in which one lives, "Haste" seems to leave exposed a hostile reality. This reality painfully affects the relationship between being oneself and the outside world. Poetry thus appears as a possible way to testify this arduous experience, as well as a way of resistance.
\end{abstract}

Keywords: testimony; contemporary; hard time.

Recebido em: 30/05/19

Aprovado em: 06/07/19

Maria da Conceição Costa de Deus Lima, ou Conceição Lima, é escritora natural de Santana, sede do distrito de Cantagalo, pertencente à ilha de São Tomé, África. Quando nasceu, no dia 8 de dezembro de 1961, seu país natal era colônia de Portugal e ainda estava a se organizar politicamente para o fim do encargo com o país europeu. Ao contexto em que Lima cresce pode-se atribuir a efervescência dos movimentos emancipatórios, a busca pela autoafirmação individual e também coletiva dos povos africanos e, especialmente, a presença da literatura como lugar substancial para a elaboração e amplificação do verbo africano. Isso, porque

não raro é apenas por via da literatura que as linhas do pensamento intelectual nacional se revelam, e se vêm revelando, em termos de várias visões sobre o país e identidades sociais, colectivas e segmentais, conformadas nas diversas perspectivas e propostas textuais. (MATA, 2006, p. 34) 
Esse contexto apresentado por Mata pode ser percebido em São Tomé e Príncipe pelo próprio percurso profissional de Lima em seu país natal. Por duas vezes a escritora teve cancelado, por ordem do governo em exercício, seu contrato com a emissora de TV responsável por transmitir seu programa jornalístico, o qual proporcionava e estimulava amplas discussões sobre as questões sociais do arquipélago. O cerceamento da palavra, assim como do debate e da elaboração do pensamento, faz parte da conjuntura social de São Tomé e Príncipe, o que, por sua vez, impõe a necessidade de deslocar ações reflexivas para outro espaço, por exemplo, o literário.

O presente artigo propõe uma leitura do poema "Haste", retirado da segunda publicação de Lima, A dolorosa raiz do Micondó (2006). Apesar das interferências já feitas no resumo deste trabalho, no que diz respeito ao caminho percorrido em tal leitura, apresenta-se o poema antes de aprofundar as reflexões a ele concernentes:

Haste

Num certo campo de um ermo lugar um caule dobra agora o dorso - verga se lhe roça o ego da intempérie.

Em qualquer campo aquém do luar num estreito canto de um país vulgar o caule cede o dorso se lhe bate a mão da ventania duplica na coluna o peso do próprio corpo.

Soergue depois a inclinação da linha e retoma o vertical instinto de sua raiz permanece.

(LIMA, 2012, p. 42)

A presença da natureza, de seus fenômenos e elementos, como se pode perceber em "Haste", é constante no universo poético da escritora são-tomense. Acredita-se que esse uso inegavelmente agracie os poemas de Lima com uma beleza, uma harmonia, as quais conferem à leitura também a sensação de deleite. Entretanto, quando se olha para sua escrita, dentre outras possibilidades, como uma escrita de resistência, de enfretamento a uma realidade nem sempre agradável, a amizade com esses fenômenos e elementos pode assumir outras feições. Há, de uma maneira geral, certa intimidade nas relações entre a natureza e o ser. Um chega a se confundir no outro, como no caso da paisagem cuja fibra se coagula, ideia presente no poema "A outra paisagem", também da coletânea $A$ dolorosa raiz do Micondó (2006). Essa volatilidade dos lugares, fazendo com que os elementos de um e de outro sejam (re)apropriados conjuntamente, 
é o que dará um mínimo de espaço para estabelecer uma correspondência entre o caule de "Haste" e o ser humano. Algumas imagens trazidas pelo poema são interessantes para ilustrar a intimidade dessas relações. O caule, por exemplo, não apenas possui um dorso - fração da anatomia humana - que verga, mas é também submetido às ações de um "ego" e de uma "mão", os quais não pertencem a um indivíduo, mas à "intempérie" e à "ventania", respectivamente. A partir desses possíveis contatos, propõe-se pensar o ser humano que também "cede o dorso" e é amparado por sua raiz. A fim de cavar um pouco mais a terra, aprofundar a interpretação oferecida, o poema é pensado em três momentos distintos, cada um pertencente a uma estrofe.

De maneira geral, "Haste" produz um forte efeito visual, pensado a partir da ideia do zoom de uma lente. No primeiro enquadramento, nos três primeiros versos, a lente está focada em um solitário ser, fixo em um determinado campo. Na estrofe seguinte, a lente se abre, outro enquadramento. De um "certo campo" o leitor é conduzido para "qualquer campo". O cenário se amplia e "o caule", não mais em um ponto fixo, apresenta localidade incerta, não se pode dizer mais, por exemplo, que ele esteja sozinho. O último momento, no qual essa dimensão espacial não existe, e justamente por isso, indica que se está a falar ali do caule, ou dos caules, de maneira abrangente.

Dentro de cada um dos três momentos de "Haste" ações são representadas e aqui entendidas como uma das maneiras do ser de se relacionar com o mundo externo, de que forma ele corresponderia aos estímulos recebidos pela realidade circundante. No entrar em contato com a "intempérie", ou ser atingido por uma "ventania", o caule "cede", "verga". Não totalmente, mas essa experiência o derruba, lesa, causa algum dano. Se se pode encontrar nesse caule alguma correspondência com um indivíduo, uma pessoa, onde buscar sentido aos estímulos e reações dentro dessa nova perspectiva? Para tentar compreender essa relação, deixa-se em suspenso a última estrofe do poema, que será retomada em momento oportuno.

O testemunho fornecido pela voz poética do canto em questão, sobre o qual se falará com maiores detalhes ao longo das reflexões que se seguem, como se ela assistisse às cenas propostas nos enquadramentos das estrofes e as relatasse, é lido nas fronteiras com a contemporaneidade, de acordo com o que diz sobre ela Giorgio Agamben (2009). Influenciado pelas ideias de Friedrich Nietzsche, o filósofo italiano também entende o termo como referência a uma "singular relação com o próprio tempo" (AGAMBEN, 2009, p. 59). O indivíduo contemporâneo é aquele que não se vê pertencente, vê-se inadequado ao seu tempo, mesmo sabendo fazer dele parte. Esse desajuste, o qual representa a singularidade, é o que possibilita ao mesmo indivíduo se distanciar, mínima e metaforicamente, de seu tempo para vê-lo de maneira crítica. Ao seu tempo de existência, vai dizer Agamben, o indivíduo

adere [...] e, ao mesmo tempo, dele toma distâncias; mais precisamente, essa [a contemporaneidade] é a relação com o tempo que a este adere através de uma dissociação e um anacronismo. Aqueles que coincidem muito plenamente com a época, 
que em todos os aspectos a esta aderem perfeitamente, não são contemporâneos porque, exatamente por isso, não conseguem vê-la, não podem manter fixo o olhar sobre ela (AGAMBEN, 2009, p. 59, grifo nosso).

A ideia de não pertencer ao tempo em que se vive não implica, porém, uma saudade do passado. Pelo contrário, o passado faz parte da temporalidade que o ser contemporâneo consegue ver, o que também possibilita sua indispensável crítica — “o manter fixo o olhar". É preciso entender que a contemporaneidade não diz respeito a um tempo cronológico específico, mas ao tempo da vida humana, o intervalo de cada ser e sua percepção diante do contexto em que está inserido. É possível perceber, por exemplo, no tempo em relação ao qual se é contemporâneo, no sentido estrito do termo, como o passado está, de diferentes maneiras, entrelaçado às feições, às estruturas e aos comportamentos que fazem a roda do mundo girar, ou melhor, que fazem a roda do mundo praticamente não girar. Algumas sociedades, em especial aquelas com histórico colonial, mas não somente, vivem ainda hoje os desdobramentos das "revoluções totalitárias da primeira metade do século XX [o século considerado das catástrofes] e suas novas formas de organização da escravidão, massacre, engodo das massas, brutalidade e horror em larga escala" (FELMAN, 2014, p. 22). Esse contexto catastrófico deixou marcas, feridas - em uma linguagem figurada - no caminho percorrido pela humanidade até chegar ao momento presente. Verifica-se, no entanto, certa dificuldade, por parte das sociedades civis e seus governos, no que se refere à elaboração dessas marcas, ao "manter fixo" e crítico o olhar para esse passado que permanece e, por isso, a roda não gira, prejudicando o fluir das reflexões indispensáveis às transformações sociais de que tanto carecemos, a sociedade brasileira e tantas outras. Ela, a roda, ao contrário, está estagnada, e assim fadada a permanecer enquanto houver o desinteresse, a recusa, pela identificação, pelo enfrentamento, pela elaboração e tratamento dessas feridas. É o que se pode identificar nos apontamentos de Seligmann-Silva sobre o contexto gerado nas sociedades que viveram ditaduras militares, um dos eventos desse passado que se disse atrelado ao tempo presente. De acordo com o pesquisador, é perceptível, por exemplo, a

[...] situação de parte da sociedade brasileira que só pode se relacionar com o passado violento da ditadura como um terrível peso, uma herança que nos oprime e que não pode ser transformada em discurso; não consegue ser processada tanto no sentido simbólico como no jurídico. Não há processo aqui; apenas estancamento. (SELIGMANN-SILVA, 2010 , p. 13, grifo do autor)

As fissuras, as marcas, as úlceras deixadas pela ditadura, e também por outros contextos, surgem, pois, de um passado que não sai de cena, que não é digerido como deveria e, por isso, tende a permanecer entrelaçado na roupagem que veste o contexto atual. Esse não processamento infalível, no sentido da intensidade de suas consequências - opressão, peso a se carregar, silêncio, injustiça —, é um dos elementos que parecem caracterizar o tempo do "agora", 
marcá-lo em suas paisagens com essas lacerações invisíveis aos não contemporâneos, segundo Agamben. O que se tenta propor aqui é a presença em "Haste" dessa ideia de contemporaneidade no testemunho poético. Tem-se acesso ao registro produzido pela visão contemporânea de Lima sobre o seu próprio tempo: "o poeta [...] é aquele que deve manter fixo o olhar nos olhos do seu século-fera, soldar com o seu sangue o dorso quebrado do tempo" (AGAMBEN, 2009, p. 60) e, portanto, soldar também o seu próprio dorso que verga, devido ao contato estabelecido com o seu "século-fera", com a "intempérie".

A escrita sobre o tempo que se vê, o próprio testemunho, é a possibilidade de dar vida a esse dorso quebrado, trazendo-o para conhecimento dos que não conseguem manter fixo o olhar para o seu tempo. A primeira estrofe de "Haste" representa este momento da escrita, em que se testemunha essa visão "por trás", deslocada, desencaixada, da realidade: "Num certo campo de um ermo lugar/ Um caule dobra agora o dorso - verga/ se lhe roça o ego da intempérie" (LIMA, 2012, p. 42).

O "agora" é o instante da palavra enquanto se escreve, e é também o tempo presente, o tempo que vigora, o contemporâneo. A percepção dessas feridas no próprio contexto em que se vive custa a ferida naquele que, em sua solitude, a consegue ver, isto é, só é possível testemunhar ferido. Por isso Agamben diz que a contemporaneidade o poeta "paga com a vida" (AGAMBEN, 2009, p. 60). Causa-lhe danos o que se está a testemunhar e o próprio testemunho, pois é em seu instante que o poeta verga. O estímulo oriundo desse contexto, aquilo que o vence, ao menos momentaneamente, é da ordem da intempérie, da desgraça, das condições desfavoráveis - o mau tempo, a opressão, o peso a se carregar, o silêncio, a injustiça. No momento em que estabelece o contato com o próprio mundo, ela, a poeta, verga.

No segundo momento de "Haste", quando o leitor é conduzido de "um certo campo" para "qualquer campo", a lente se abre, como já dito. O alargamento da perspectiva é o que permite considerar outros elementos, outros caules, outros indivíduos, em cena. Junto a Lima estão os que vivem submetidos a um mesmo contexto, a um mesmo tempo. A questão é que esses outros elementos também cedem o dorso quando sentem a opressão de seu próprio mundo. No entanto, nem sempre conseguem testemunhá-la, o que intensifica tal experiência. Testemunhar não cura a úlcera, mas aqueles que não testemunham veem tornar duas vezes maior "o peso do próprio corpo". Por isso o testemunho é visto no século das catástrofes como elemento fulcral para a elaboração dessa experiência nociva entre o ser e o mundo exterior: "Pelo fato de o testemunho ser dirigido a outros, a testemunha, de dentro da solidão de sua própria posição, é o veículo de uma ocorrência, de uma realidade, de uma posição ou de uma dimensão para além dele mesmo" (FELMAN, 2000, p. 16, grifo da autora). O ser contemporâneo testemunha o mundo para o mundo, "para além dele mesmo", pois o mundo precisa saber de si. Percebe-se, ainda com Felman, a importância do testemunho nessa leitura do contemporâneo como contexto penoso, doente: 
[...] o que existe para testemunhar urgentemente no mundo humano, o que alerta e mobiliza a atenção da testemunha e que necessita do testemunho, é sempre, fundamentalmente, em um sentido ou outro, o escândalo de uma doença, de uma doença metafórica ou literal; e que o imperativo de testemunhar, que aqui deriva do contágio da peste - da erupção de um mal que é radicalmente incurável —, é em si, de alguma forma, um correlativo filosófico e ético de uma situação sem cura e de uma condição radical de exposição e vulnerabilidade humanas. (FELMAN, 2000, p. 17, grifo da autora)

É fundamental perceber que a doença ali representada, "metafórica ou literal", diz respeito não apenas aos que sofrem diretamente as suas manifestações, mas a todos os que compartilham uma época. O mau tempo está no céu de todos. O testemunho poético de Lima traz em si "o escândalo de uma doença", cuja deflagração faz emergir uma situação "de exposição e vulnerabilidade humanas".

Isto que se está a chamar de doença, de úlcera, de fissura, essa quebra da estrutura, essa ideia de algo que é interrompido, é o lugar possível de perceber o passado estagnado, pois ele se encontra justamente nessa quebra, nessa pausa, nessa interrupção dos acontecimentos da história dentro da questionável "homogeneidade inerte do tempo linear", como sugere Agamben (2009, p. 71). A temporalidade humana, mais uma vez, não diz respeito a um tempo cronológico, cujo desenrolar segue por uma linha reta, em uma ordenação certeira e controlável. Quando o contemporâneo vê a sua temporalidade, a paisagem parece apresentar, ao contrário, inúmeras descontinuidades, rasgos, fissuras, frágeis emendas. Nesse tempo de dorso quebrado, é justamente no desvio que o passado se aloja.

Durante uma fala para o canal do Café Filosófico, em 2017, intitulada "Relações humanas no mundo contemporâneo: testemunho como chave ética", o professor da Universidade de Campinas Márcio Seligmann-Silva apresenta uma sequência de produções de alguns artistas plásticos e fotógrafos, os quais trabalham com a recuperação de objetos de alguma maneira associados a eventos de caráter violento, destrutivo, como os campos de concentração nazistas e as ditaduras militares. Um pente sem dentes encontrado em um Lager, outra denominação para os campos de concentração, ou uma fotografia antiga da turma de escola do próprio artista, da qual ele se (re)apropria para inscrever, registrar, aqueles seus amigos torturados, mortos ou desaparecidos durante o regime militar em seu país. Por isso, essas manifestações artísticas, produzidas recentemente, podem ser vistas também como elaboração do luto: "as pessoas não são enterradas no século XX", afirma Seligmann-Silva (2017). O que importa destacar aqui, na fala do professor, é sua perspectiva de que a arte pode "nos despertar para o outro", transformando "objetos banais", produzidos por esses contextos, "em testemunhos poderosos", produtores de memória.

Sendo assim, a fim de oferecer outro caminho para a compreensão da abstrata ideia de temporalidade quebrada, busca-se ajuda em uma peça de arte exposta no Museu de Arte de São 
Paulo, como parte da exposição "Histórias afro-atlânticas" (de 29 jun. a 21 out. 2018). Trata-se de uma tapeçaria do autor ganês Ibrahim Mahama, criada em 2017.

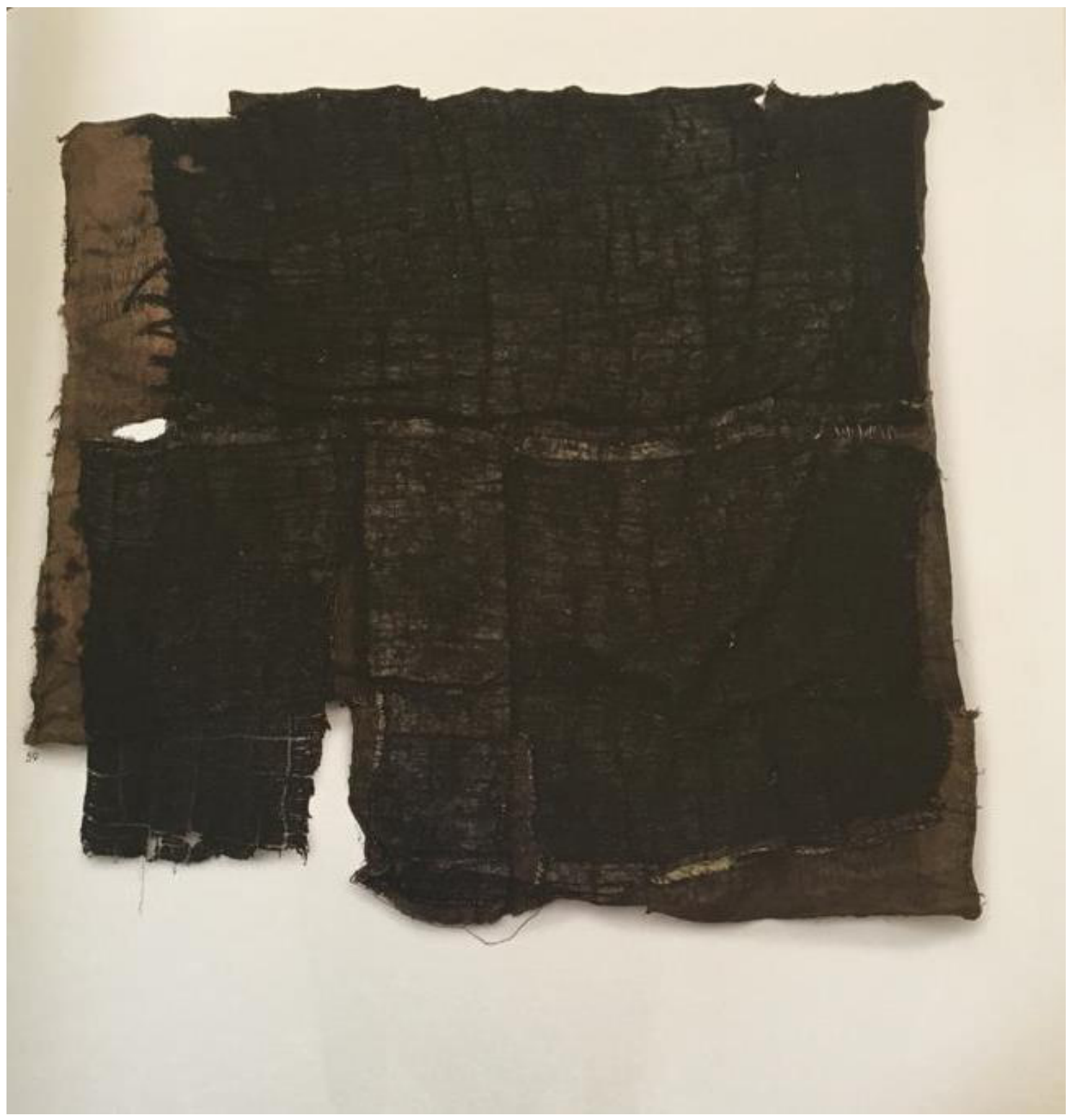

Hamida. Fonte: Histórias afro-atlânticas; catálogo, 2018, p. 43.

A matéria-prima utilizada pelo artista é a juta, fibra vegetal empregada na produção de sacos. Como explica o catálogo da exposição, a

[...] rica e elaborada tapeçaria, cheia de finas e violentas marcas do colonialismo e da escravidão, contrasta com a rude, áspera e escura obra de Ibrahim Mahama, Hamida (2017). [...] Esses sacos feitos no sudeste asiático para transportar cacau ganês, são reutilizados para carregar produtos de diferentes naturezas e inseridos no cotidiano 
do país africano. Desse modo, o deslocamento do tecido faz com que ele absorva as duras marcas da viagem, revelando uma pátina, uma espécie de refugo das intensas transações globais que atravessam norte e sul, ocidente e oriente, e que passam por Gana (SÃO PAULO, 2018, p. 37).

A peça de Mahama é aqui considerada também como testemunho da contemporaneidade, da relação estabelecida entre o artista e o seu tempo. Há um remendo de fragmentos do passado ainda "inseridos no cotidiano do país africano". O resultado desse remendo é o próprio testemunho, é uma outra maneira de revelar a paisagem, de responder aos estímulos de um tempo ele mesmo remendado, cheio de falhas, fendas, buracos, "marcas". A tapeçaria de Mahama, acredita-se, evoca o caule cujo dorso se quebra de Lima, e vice-versa, pois cada um, à sua maneira, testemunha sua visão contemporânea de uma mesma época. E o passado, para ambos os casos, é elemento fundamental para seus testemunhos. No caso do artista ganês, os sacos de juta são a própria evidência desse passado e das texturas, fissuras, buracos que ele causa no próprio testemunho; é ele mesmo o que dá vida ao testemunho. A tapeçaria de Mahama só existe pelo passado que nela foi costurado. Interessante pensar, quando se considera o que foi dito anteriormente sobre testemunhar não ser a cura da úlcera, que "Hamida" não demonstra uma recomposição simétrica, perfeita e bem executada a ponto de mascarar ou tentar esconder os desgastes do tempo. Pelo contrário, as falhas, as frágeis costuras - quase soltas os rasgos, todos eles fazem latejar ainda mais a força desse passado no presente, deflagram essa úlcera, deixando também o testemunho marcado. No caso de Lima, o passado está na raiz, cuja presença é responsável por manter vivo e ereto o caule, por fazê-lo resistir ao que lhe causam as intempéries - o mau tempo: "Soergue depois a inclinação da linha/ e retoma o vertical instinto de sua raiz —- permanece (LIMA, 2012, p. 42).

Essa referência ao passado, sua entrada em cena, é construída de maneira a indicar duas questões. A primeira delas tem relação com essa ideia de que na raiz está a sobrevivência do caule, é nela que o ser vai buscar o seu instinto de manter-se de pé, resistindo a outras eventuais curvaturas em seu dorso. A segunda questão diz respeito a uma responsabilidade por parte daquele que consegue testemunhar o próprio tempo: "Se, como vimos, é o contemporâneo que fraturou as vértebras de seu tempo (ou, ainda, quem percebeu a falha ou o ponto de quebra), ele faz dessa fratura o lugar de um compromisso e de um encontro entre os tempos e as gerações" (AGAMBEN, 2009, p. 71). O contemporâneo deve à sua capacidade de ver, pois às suas condições de existência ele não se adéqua perfeitamente, o compromisso de transformar a percepção desses pontos de quebra em material reflexivo para a transformação desse tempo. Junto a esse compromisso está o encontro com "os tempos e as gerações", ou seja, o encontro com o passado. Por isso Lima atribui a resistência do caule à raiz, é nela que está a força, a potência, a própria possibilidade de arcar com esse compromisso. 
De maneira geral, pode-se dizer que as perspectivas de leitura oferecidas e as fontes trazidas para o diálogo se fundamentaram na tentativa de acompanhar o que se ouviu da voz poética de Conceição Lima, especialmente no que se refere ao convite à reflexão sobre o contemporâneo, sobre o mau tempo que nos acomete a todos. Dentre tantas questões relevantes que os poemas da escritora podem despertar, essa, a da reflexão, parece ser a mais marcante: é urgente direcionar o olhar para o passado, de modo a ver nele o que se precisa elaborar para transformar o presente.

Espera-se que de alguma maneira este testemunho do testemunho poético de Lima possa se desdobrar novamente, produzir outras reflexões. Em certo momento de um dos trabalhos de Felman, há uma menção ao prêmio Nobel de Literatura de Elias Canetti. Eis as palavras do escritor reproduzidas pela pesquisadora israelense:

Em face do horror da vida - por sorte a maioria das pessoas o nota apenas ocasionalmente, mas algumas, para quem forças internas exigem um testemunhar, estão sempre dele conscientes - existe apenas um consolo: seu alinhamento aos horrores experimentados por testemunhas anteriores (CANETTI apud FELMAN, 2000, p. 15).

Elaborar discursivamente a experiência com a poesia de Conceição Lima é também produzir um outro testemunho sobre esse mau tempo.

As reflexões aqui tecidas, no entanto, permanecem, seguem tentando fazer a roda girar. Aprendemos que se deve manter fixo o olhar. Esse posicionamento, inclusive, coloca próximas a poesia de Lima e as discussões sobre a literatura de testemunho. De uma maneira ou de outra, ambas parecem movidas pelo desejo de construir novas maneiras de nos organizarmos socialmente, tendo como pressuposto ético sermos todos humanos e, por isso, iguais, em direitos e deveres. Esse parece ser um dos pilares dessa construção. No entanto, tal empreitada se torna impraticável sem a participação e o envolvimento de todos, como nos testemunha Primo Levi, um dos sobreviventes dos campos de concentração nazista, ao relatar sua experiência: “A necessidade de contar 'aos outros', de tornar 'os outros' participantes, alcançou entre nós, antes e depois da libertação, caráter de impulso imediato e violento, até o ponto de competir com outras necessidades elementares" (LEVI apud SELIGMANN-SILVA, 2008, p. 66). Esta produção acadêmica é fruto de uma tentativa de participação - de escuta, de envolvimento a qual foi possível a partir dos caminhos que Lima oferta para nos deixar ver sua dolorosa raiz e nos fazer também sentir, enquanto contemporâneos, o roçar da intempérie, o mau tempo.

\section{Referências}

AGAMBEN, G. O que é o contemporâneo? e outros ensaios. Tradução: Vinícius Nicastro Honesko. Chapecó: Argos, 2009. 
FELMAN, S. Educação e crise, ou as vicissitudes do ensino. In: NESTROVSKI, A.; SELIGMANN-SILVA, M. (orgs.). Catástrofe e representação: ensaios. São Paulo: Escuta, 2000. p. 13-71.

. O inconsciente jurídico: julgamentos e traumas no século XX. Tradução: Ariani Bueno Sudatti. São Paulo: EDIPRO, 2014.

LIMA, C. A dolorosa raiz do Micondó [2006]. São Paulo: Geração, 2012.

MATA, I. A crítica literária africana e a teoria pós-colonial: um modismo ou uma exigência? Ipotesi: Revista de Estudos Literários, Juiz de Fora, v. 10, n. 1, n. 2, p. 33-44, 2006.

SÃO PAULO (Estado). Secretaria da Cultura; Ministério da Cultura. Histórias afro-atlânticas: catálogo. São Paulo: Museu de Arte de São Paulo Assis Chateaubriand, 2018.

SELIGMANN-SILVA, M. Narrar o trauma: a questão dos testemunhos de catástrofes históricas. Psicologia Clínica, Rio de Janeiro, v. 20, n. 1, p. 65-82, 2008.

. O local do testemunho. Tempo e argumento: Revista do Programa de Pós-graduação em História, Florianópolis, v. 2, n. 1, p. 3-20, 2010.

.Relaçõeshumanasnomundocontemporâneo:testemunhocomochaveética.SãoPaulo:TV Cultura, 2017. Disponível em: https://www.youtube.com/watch?v=ZE0GqiYLFWY\&t=2988s. Acesso em: 28 ago. 2018.

\section{Minicurrículo}

Camila Dias de Souza Christo Aleixo é graduada em Jornalismo pela Universidade Federal de Ouro Preto e mestre em Estudos da Linguagem pela mesma instituição. 